\title{
THE INTEGRATION OF RELIGIOUS THEORY AND THE THEORY U IN EDUCATION: A HUMAN CAPITAL DEVELOPMENT IN THE BUSINESS DISRUPTIVE PARADIGM
}

\author{
Kannapat Kankaew
}

Suan Sunandha Rajabhat University, Bangkok, Thailand

The four major forces of Ts are pushing us to globalization faster. These are technology, television, trade, and travel. It is worth noting that the forces of four Ts also turn us into the global economy where firms are competing globally. Organizations can either acquire technologies, or reproduce their more advanced version but within a few years. We would suggest adding one more $T$ which is telephone since it has influenced our life in so many ways. Today, smartphones are shaping mankind behavior in a very significant way. Thailand is currently developing its Thailand 4.0 concept with multiple projects to upgrade from middle-income economy (in which it is trapped now) to value-based economy. The aim of this academic article is to create the theoretical framework of human capital development ready for disruptive economy where certainty is substituted by uncertainty. We also point out to the alignment of Buddhism concept and various Western theories, including Theory $U$, institutional theory, knowledge management and best practices within the educational system. Today Thailand should be out looking for its new normal with an open mind and open heart and willingness/readiness to develop its human capital further, using goodness, ethics and moral, knowledge and skills, creativity and innovation.

Keywords: human capital development; disruptive economy; religious education; Thailand 4.0; Theory U

\section{Introduction}

Globalization has emerged in the mankind history long time ago, becoming the power to defeat and conquer. In simple terms, it can be explained as bigger countries conquering smaller countries to make them colonies. In such a way, larger countries were taking advantages of resources, money, government and they also control norms and values.

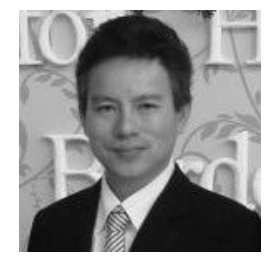

\section{Kannapat Kankaew}

Assistant Professor in department of airline business at International College; Suan Sunandha Rajabhat University.

His interest research in air transportation, human resource management, learning \& education, and services.

Published more than 25 papers in international journals.

E-mail: kunnapat.ka@ssru.ac.th 


\section{THE INTEGRATION OF RELIGIOUS THEORY}

This kind of globalization can be viewed as savage conquering. Present day type of globalization has evolved through the use of mostly economic means, including monetary policy, open free trade, investment and funding. Developed countries have better capabilities and knowledge of the business environment. Furthermore, they have higher purchasing power within the perfect market (Pawet, 2002).

Bigger countries could control other, smaller countries by implementing the sanction policies against rebellious states, and call it legitimate action. This is logical succession of the globalization trends of the past, but today countries employ the power of money instead. Nowadays, robotics and artificial intelligence (AI), agile changes, big data and information analytics have become those powerful tools that can disrupt all types of business.

Therefore, in this postmodern world, both countries and organizations have to prepare own plans for future endeavor, especially related to their human capital which AI still cannot replace. Human capital is the most essential resource of every country as it is responsible for competitiveness and growth of nations. As it is stated in (Abell \& Oxbrow, 2001), knowledge economy is new reality for both nations and firms. The states increasingly depend on the competencies and intellect of their people.

According to (Jasimuddin, 2012), ICT advancement has generated crucial volume of knowledge in today's economy. Notwithstanding all positive effects of knowledge on human development, there are also at least three major science concerns regarding it. These concerns are scientific because people today are living surrounded by with various types of materials. Another aspect concerns social sciences since humans are constantly connected with other people and they are also governed by rules and regulations. And finally the third aspect concerns humanities sciences, as all humans need to recognize the goodness, responsibility, integrity and common human values.

We all shall also comprehend that education generates self-awareness, improves social context involvement, and links people with the environment. All these multiple aspects of learning are inseparable from our lives in various places across the globe where we live connected with each other through actions and reflecting on these actions that we make (Changkwanyeun, 2017).

Changkwanyuen also suggested that the philosophy of religions, both Western and Eastern, should be better integrated into both educational systems and the research process. He claimed that many Western scholars have already appreciated the special value of Buddhism being beneficial for scientific search and also for academic professionalism. On the other hand, to be more productive and successful, teachers should adopt religions for teaching and learning. Beyond this, it is universally known that every religion teaches people to be humans, first of all. It means being good people, with merits, sharing, donating and contributing to society.

\section{Theoretical Analysis}

\section{The disruptive paradigm of changes and human capital development}

Thailand 4.0 project being currently adapted in the country is causing a disruptive wave of changes. The key purpose of this huge project is to transform economy into a value-based one which is switching from products to innovations.

The most essential driver of this national project is human capital. In this context, human capital covers: knowledge and soft skills, high-quality education, self- and social 
awareness, life-long learning and fundamental qualifications (Kankaew, 2019). D. Ushakov (2018) pointed out the knowledge, skills and information that a person has gained through their life span become a long-term investment of highest value for the postindustrial era.

Evolution of the human resource management (HRM) concept was stemming from the need to enhance the quality of working conditions for workforce under the behaviorism theory. From then onward, the science of HRM was expanded because scholars believed that HRM could seriously support organizations' performance (Aston Centre for Human Resource Management, 2008). Later, the concept of human capital came from the idea of (Schultz, 1980) and his book "Investing in people: The economics of population quality".

There are numerous ways to invest in people, for example: in their formal education, in learning from home, in the development of skills which are accumulated from work experiences, in healthcare for children and adult working population etc. Such investment would change the quality of people's potential, their quality of life and make them more productive.

Becker (1993) defined human capital in several heterogeneous dimensions: the quality of life depends on the current activities of people which also partially reflect the potential future of individuals in its diverse aspects including: income, mentality, purchasing power and many more. Thus, human capital investment could include: training, education, healthcare, development in the most general sense, joining various seminars, listening to various online and offline lectures, simply doing good things and shaping own integrity, developing personal punctuality etc. These all activities could eventually bring higher salary but in a short term they also assume higher expenses of individuals which should be seen as investments. Another important factor for human capital and its development is family, since parents always directly participate in shaping of knowledge and delivering cultural norms to their children.

Wykstra (1971) mentioned that capital resources were only one of many factors in organization of production, the key role of capital is to determine the cost of all other resources. At the same time, human capital is one of the core elements of the economic development process. Its quality can be greatly improved through formal education, improving people's health and better choice of occupation.

Thai economist (Boonkong, 2006) described human capital as acquisition of knowledge and skills for the purposes of adding extra value and also for higher productivity. Values, in this context, can be both tangible and intangible, for example, cognitive capabilities and problem-solving skills are all intangible. Human capital also strongly depends on personality traits and even on feelings, besides that, much depends on the art of communication. From the academic perspective, human capital refers to knowledge, abilities, skills and capabilities that coexist inside organizations.

The largest share of all competences and skills come from two sources - formal education and additional training. In other words, some of them come to an organization from the outside and others are obtained from the experience in a workplace itself. Human capital is also often compared to a mechanism creating knowledge within an organization. Finally, human capital could be viewed quantitatively or qualitatively. The quantitative aspect refers to the number of workforces in an organization, while its qualitative aspect means knowledge and skills that are affecting job performance (Dzinkonski, 2000; Razi \& More, 2012; Ananmana et al., 2018; Kraaijenbrink, 2011). 


\section{THE INTEGRATION OF RELIGIOUS THEORY}

Travel, trade, technological advances and information communication technology (ICT) together are making the world more flat, or globalized. The nations are moving forward, trying to prepare themselves for the uncertain world and its fast pace of changing. Developed states have more opportunities in this regard since better economy always means higher quality of human capital. However, a set of smart skills which would fit this new century along with a positive attitude is highly required for any country, actually.

At the individual level, this would be translated into mindfulness, discipline, respect to regulations set by the society, ethics and moral. In other words, developing human capital is not only about improving competencies within the observed behavior but on a deeper level psychological state of a person is no less vital. In this context, life-long learning is a must since only this mode of getting education can catch up with the pace of technological development and with knowledge economy overall. As a result, today, many organizations are becoming learning organizations in which employees are free to learn and share knowledge with each other. Some organizations have set up their own learning centers which become integral part of their competitive strategies.

According to (Hoy \& Miskel, 2005), today's organizations are complex because they are functioning like networks of social relations. Thus, to understand the context of an organizational system one must have a holistic view on the whole system.

Business organizations become identical to schools as they are providing teaching and learning activities, while their participants are improving their abilities to create. Same authors (Hoy \& Miskel, 2005) in this regard focused on three key theories of learning with different focal points, namely:

(1) behavioral theories, with the emphasis on observing changes in behavior, skills, and habits;

(2) cognitive theories which are concentrating on thinking, remembering, problemsolving, creating, etc., and lastly

(3) constructivist theories that explain how individuals make the meaning of events and activities, and that learning is kind of building knowledge. Therefore, learning occurs when experience cultivates changes in one's knowledge or behavior.

\section{Buddhism concept as applied to mankind development}

In Buddhism, learning known as Sikkhā means to educate or develop human behavior . In Buddhism, we have to understand human behavior before providing instruction. The former consists of karma which refers to the three actions: (1) all physical activities from the physical movement called Käiyakam ; (2) all verbal activities called Wačhīkam ; and (3) all type of thoughts occurring in our mind , such as believes, thoughts, standpoints, abidance called Manōkam. The most important action is the thought (Manōkam) because the thought is the very beginning process of attitudes, norms, values, doctrines, theories and goals which together are called thitthi. Thitthi, in its turn, will direct and lead our actions, whether good or vicious.

Man perceives experiences and keeps information from the surrounding context using five senses called Ayatana - or eyes, nose, ears, physical, and tongue. These experiences are important because they lead us to cognitive actions and/or construct knowledge which is later leading the way of our life. In other words, if we are happy from what we have sensing, we would do the same thing in response to our need of happiness. This is called Tanha. The reaction of Tanha leads us to the choice of what we prefer, good or bad. The mankind needs 
education to understand profoundly own head, hands and heart, and how their response to the needs might affect the living of others. It might be hazardous to other lives, for example, to people, animals and the environment overall. This reaction will later return to the person who committed the wrong, hazardous action.

Thus, Sikkhā is the light which improves human behavior , mind, and intellect. These three - behavior, mind and intellect - could never be separated. Hence, education in Buddhism is to develop the mind free from any agitation and/or temper that leads to the feeling of unhappiness. Just observe it, and that temper feeling will be soon gone. When an individual confronts the unwanted situation, he/she knows that the cause of the situation is from their own past (karma).

Thus, an individual shall focus on their present activities since doing something good today means good future. This is also the reason for human education. Once people understand the consequences, they could choose their habits of living, for instance, selecting good food for health. These changes in human behavior are called Panyā or wisdom . Panyā helps individuals with responding to anything that provoke negative sensation.

Traisikkhā is the process of huma $\mathrm{n}$ development consisting of three elements : Sila (discipline), Samāthi (meditation) and Panyā. Sila is a mechanism to control behavior through self-discipline. It is the beginning of learning in everything what is related to human mind (Phraphromkhunaaphọn, 2010, 2004).

As (Goenka, 2019) stated, sila covers five fundamental rules of Buddhism, namely: (1) abstaining from killing live beings, (2) abstaining from stealing, (3) abstaining from sexual adultery, (4) abstaining from telling lies and (5) abstaining from all forms of intoxication . In considering that Samāthi (meditation) is about practicing human mind by observing feelings that arise in our own mind, just observing until that feeling is faded away and a new sensation arises and also fades away, and so on. There is nothing stable for the eternity.

This learning how to meditate helps to prepare ethics and moral as well as mindfulness. In a longer term , this forms more rational thoughts and also helps with analyzing the environment. Panyā is about seeking intrinsic truth by experiencing the reality of mind, observing the negativity as it arises and confronting it. Soon mental impurity will lose its strength and slowly fade away. In a similar way, miseries from others' irritation and disharmony could distribute to oneself since all of us live in a society and we are dealing with each other on a regular basis.

Wātsanā or personality traits is another issue that a man can develop through learning . It means the accumulated behavior of an individual which becomes a habit or personality traits, for example, the way we walk, talk, sit, stand, etc. Wātsanā has a strong influence on the people around us, as they start either liking, or disliking our personal traits. As humans living in a society, we need to practice good manners to support our better living (Phraphromkhunaphọn, 2010, 2004).

In this human-in-a-society context (Pawet,2002) proposed that the whole world can live peacefully together within a new normal of imagination. He considered that imagination comes before knowledge, as man can imagine without boundaries. Thus, imagination becomes a power to construct new knowledge. All human beings and all other forms of life are living in the same world, and together they form 'the same onenesses. If something gets demolished, others would be affected too.

Correspondingly, we all will eventually lose harmony. Humans have enough power and spirit to survive in the nature but for this we need to sacrifice and/or help other people, then 


\section{THE INTEGRATION OF RELIGIOUS THEORY}

the endorphin of happiness will be released. This endorphin would generate spiritual happiness which would make us all become healthier. If a person loses spiritual happiness for some reason, that person would also lack self-actualization and will began searching for it. The society as a system is diverse, but it is also an integrity of diversity.

Three dimensions of it should be considered here:

(1) expanding spiritual relatedness of the social world,

(2) building the social fundamental structure similar to how body consists of cells that are connected and work systematically,

(3) construction of a universal communication system in which all people are able to know the same facts.

We have to understand the reality of the environment in which everything is dynamic and interconnected. It is a new type of consciousness since each individual at a different life stage has distinctive consciousness of mind. Harmonious mind will let us be free from defilements and will stimulate universal love and understanding with others.

In summary, the Buddhism concept of human capital development emphasizes on the consciousness level or in other words - on human mindfulness. This would reflect on the behavior of individuals, self-awareness and conscious decision-making of not committing any harm to any live being. In the meantime, when temptation or defilement arise - just observe it. Soon this temptation will fade away.

Human sensation can be contiguous to others, whether it is positive, or negative. If we have a pure, peaceful and conscious mind, we can create, innovate or generally operate in a good for organization way. People around us will sense our feelings.

Thus, new knowledge might come up to solve the existing problems which are quite necessary for today's knowledge-based economy and the disruptive business world. These days, most organizations become learning organizations so that they share, develop; train their workforce in order to get new competitive advantages. Other institutions also practice knowledge management through searching for best practices to be applied in learning, teaching, research and innovation.

\section{Knowledge Management (KM) and Institutional Theory}

Learning organization is the organization which lays emphasis on learning. There are continuous changes on the way to firm success. On boarding new employees usually assumes both internal and external training. Specific technologies can be also implemented for training purposes to optimize the learning process.

Generally speaking, there are five subsystems in learning organization: (1) learning subsystem, (2) organization subsystem, (3) people subsystem, (4) knowledge subsystem, and (5) technology subsystem. These five elements together make sure the organization is achieving its objectives. These five elements also support each other in the course of learning. If one subsystem fails, this would definitely impact other subsystems.

Knowledge management (KM) integrated with technologies is in the heart of developing learning organizations. It consists of six processes: (1) knowledge acquisition, refers to the collection of information and data from both internal and external sources, (2) knowledge creation, or new knowledge that may come from various kinds of activities, including research, innovation, new and related business perspectives, (3) storage refers to keeping valuable knowledge of an organization and coding it in order to make sure that only employees can access it at any time and anywhere, (4) analysis and data mining referring to 
the techniques used to analyze information, while data mining helps organizations find the needed information easier, (5) transfer and dissemination which mean delivering the whole volume of knowledge all over organization, (6) application and validation which mean adaptation and assessment of knowledge by an organization, which is considering the usage of valuable knowledge to innovate continuously (Marquardt, 2002).

At the same time, (Senge, 2006) determines a learning organization as the one in which workforce is able to expand their competences regularly at the individual, team and organization levels. This concept of Senge got the name of "The Fifth Discipline". It covers: (1) system thinking; this is the way of thought from material input to final output, (2) personal mastery as referring to how employees perceive the importance of learning, training and practice, preferably in the context of life-long learning.

The organization should create the environment to support its workforce in development and renovation of their capabilities, (3) mental model which means thoughts, beliefs and attitudes from the experiences accumulated until they become a concept. Availability of a concept helps individuals understand and synthesize information better, and thus make more proper decisions, (4) shared vision means the construction of a common, people's perspective in organization with the same goals, (5) team learning is the dynamics of learning as a group. The main key here is sharing and exchanging knowledge. In addition, it emphasizes the importance of teamwork and collaboration for problem-solving.

$\mathrm{KM}$, presently, is quite popular because many organizations and institutions are interested to find out best practices. At some level, it is a kind of isomorphism from the institutional theory of DiMaggio \& Powell (1983) as cited in (Thippawan, 2013). According to (Thippawan, 2013), organization is influenced by both external or internal environments, including society and government. This influence forms the basis of legitimacy for the organization to survive. There are three factors enhancing isomorphism here: (1) Coercive isomorphism is reproduction from both formal and informal forces, for example, rules \& regulations; (2) Mimetic isomorphism which takes place due to uncertainty in the environment. The organization will imitate or benchmark best practices of some organization which is seen as a model; (3) Normative isomorphism refers to the reproduction, traditional for professionalization, set up as a group of rules and working processes beneficial for legitimacy and autonomy in a career. Professional isomorphism consists of two major keys: one is formal education, usually affiliated to a university or similar educational institution.

The other is growth of professional networking that strengthens all types of organizations. (Donaldson, 2001) disagrees with the concept of finding "one best way", since each organization has its own style which depends on the contingency of market changes and the available technology. Simply put, this means there are more than one choice of theory to achieve success in business or education.

In conclusion, the author would like to highlight that in Thailand, KM practices within the education system derive from this isomorphism. There is hardly any adaptation to the culture, local beliefs and norms. There are also some similar challenges when applying KM in Thai organizations. As self-oriented human beings, we would like to keep knowledge more to ourselves rather than share it with others, especially if these others are in the same position with us. In Thailand, people who are open to sharing their knowledge will be often seen as being very innocent rather than they will be praised for that. 


\section{THE INTEGRATION OF RELIGIOUS THEORY}

Moreover, tacit knowledge as such is not easy to express and share with others (Jasimuddin, 2012). At the same time, from the perspective of this relatively new concept of learning organizations, the concept of the fifth discipline as in (Senge, 2006) actually has some similarity with Buddhist system thinking and mental model. If we can see a thing as a wholeness, this might reduce the limitation of KM challenges.

Preparing this article, the author has found another interesting theory which has some similarities with Buddhism, this theory is called Theory U by (Scharmer, 2004). The theory explores a hidden dimension of social process that humans confront every day. This theory is relatively new to science. Albeit, the purpose of theory $U$ is suitable for leaders, individuals and even groups that are engaged in creating innovations and/or implementation of changes. The author is confident that we can adapt Theory $U$ to learning and teaching for Thai students, notably in relation to such concepts as deepest mind and consciousness.

\section{Theory U}

The idea of (Scharmer, 2009) stems from the three kinds of rises:

(1) the rise of global economy which has three factors involved: globalization of capital which has led to serious socioeconomic transformations in the USA, Japan and European economies, including the liberalization of trade rules in the first place. The other factor is global expansion of firms. These firms have been looking outside rather than inside, in their search for research for innovations. The last factor is technology, ICT in the first place. During the last century ICT have radically changed from being small networks to becoming world wide web which is connecting the entire world. Moreover, ICT are still moving today to transform technologies into biotechnologies.

(2) The rise of network society is directly related to globalization of governance, i.e., today's economy is ruled by the global-level institutions such as the World Bank, the International Monetary Fund (IMF), the World Trade Organization (WTO). Besides, network society is becoming conjoined with political institutions while the latter become bargaining agencies despite their previous power to conquer. Yet, the dark side of a network society is that it fully excludes people who lack the right knowledge, skills, and are unable of social networking. As a result, these people would eventually face lifetime unemployment, thus, they would fully lose social security as they would become powerless to bargain. Living without social capital can ruins our life, since social capital is the energy source for life satisfaction. And finally,

(3) the rise of a new consciousness, or spirituality, which is also a fundamental source of human creativity in which human experience is segregated from religion and believe. From the sociological point of view, spirituality is formed in a small group of people that regularly meets, providing support and care for each other in the group. However, only a friction of this group's interests and activities is church-related. It is also a community that has interests in personal mastery, dialogue, and other communication flow.

Scharmer (2009) also stated that the business world has gradually shifted from (1) product-driven economy to (2) service-driven economy and now we are experiencing (3) knowledge- and innovation-driven economy.

Majority of institutions around the world today are trapped to find new solutions to the changes that are happening too quickly. In doing so, they often focus on decentralization and 
finding more opportunities for networking; they also invest more in their organizational structure and then appreciate the value added from the creation of the whole ecosystem.

This is frequently called the economy of scale, or the economy of scope. There is also place for more traditional push and pull factors. Push orientation usually means the relationships based on the traditional worldview of things outside us, and has no influence from our thoughts or behaviors, while pull orientation means more external worldview with a stress on customers, stakeholders and social complexity overall.

Lastly, presence-based view means the company commences to the next level/stage when seeing the need to develop skills to deal with a chaotic situation. At this, the inner source of creativity is not individual, it is present in all parts of an organization. So, Scharmer (2009) proposed the inner territory of leadership called "U". It moves to cognitive spaces with 7 steps of profound processes for innovation and change (as illustrated in Fig. 1).

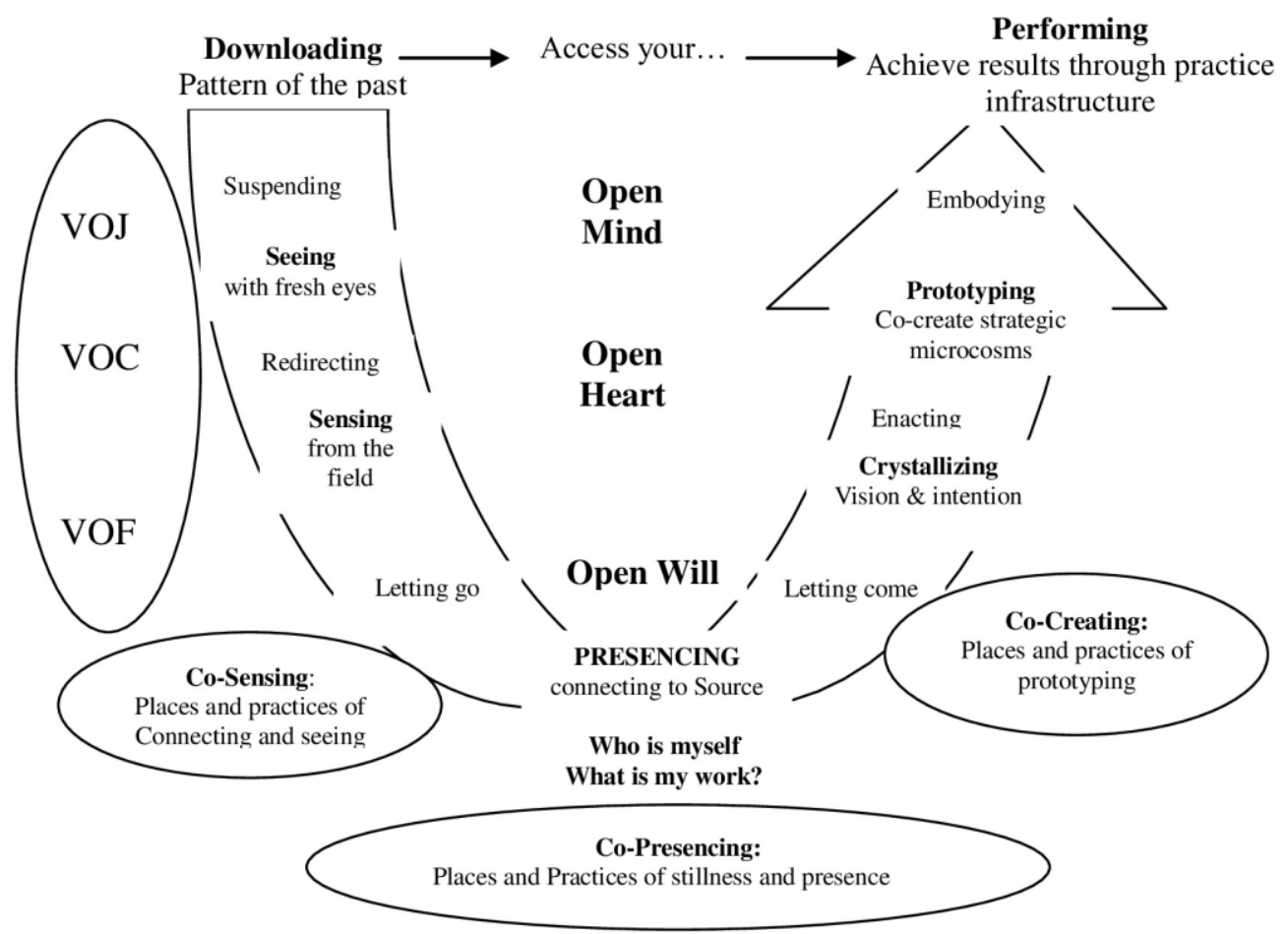

Figure 1 -Theory $\mathrm{U}$

(Source: Scharmer, 2009)

From Figure 1, it is rather obvious that the Theory $U$ and its author have been seriously influenced by Eastern religions, Buddhism especially. This theory of Scharmer aims to advise leaders, individuals and/or groups who generate creativity and change, those who wish to create something new and bring it out globally.

One of the key assumptions in this theory is that humans have a blind spot when it comes to noticing structure. Also, humans tend to concentrate on finished goods or strategies rather than on the insights how to reach them and what leaders do to achieve results. In society, people are usually aware of what, how they do, and thus react respectively. 


\section{THE INTEGRATION OF RELIGIOUS THEORY}

Normally, there are two types of learning: one comes from the past experiences, and another is from the future as it first appears in imagination. However, learning from the future emerges being yet unknown.

Theory $U$ is trying to explain the phenomenon of this journey of an innovative thought that shines out. As we can see from the shape of the letter $U$ itself, it goes to the deepest level of regenerating which is beyond observation, reflection, planning and acting. The philosophy of freedom stresses on senses, observation and perception as an initiative step in any question that arises. Or in other words, the focus is on the consciousness of a person.

Yet, Theory $U$ serves the collective attention. The logic of this theory covers 7 cognitive spaces. The starting point of $U$ is going downloading: acting according to the patterns from the past or noticing the world through individual habits and thoughts; (2) Seeing: holding judgement and seeing the fact with fresh eyes, or observing the system separately from those who observe; (3) Sensing: connecting and attending to the whole situation so that the differences between the observer and the observed fade away while the system starts to see itself; (4) Presencing is viewing from inside the source, connecting to the deepest source so that the future begin to arise; (5) Crystallizing vision and intentions and then conceptualizing the new ones from the future to emerge; (6) Prototyping living microcommunity to explore the future by doing, or enacting the new through the dialogue with the universe; (7) Performing and embodying the newness in practices and basic structure, embedding newness in the context of bigger co-evolving ecosystems. From the holistic view on the cognitive $U$ spaces, the theorist believed that most of institutions and firms are using only some part of the U.

For this very reason, they tend to struggle at the downloading, seeing and sensing levels. There are two keys, important for deeper knowing of the conscious mind. Firstly, segregating between the types of cognition, one is normal and another one is at deeper level. Secondly, going to deeper level of knowing by observing deeply. After that, one is able to connect to whatever they want to arise, and then act accordingly.

Meanwhile, to become aware, we need to practice Samatha. The instruction of Pra Shakyamuni (Lord Buddha) to do samatha is to suspend, redirect and then letting it go. Suspension here refers to the engagement and seeing your habitual patterns entirely. This process often involves meditating. Then, redirection is turning your attention to the interior origin of a mental process rather than to the exterior object. And letting it go means accepting the experience that occurs. After that, one would be allowing something new to come, something that is emerging from the future being already purposeful.

According to (Scharmer, 2009), developing a profound innovation, a change or an initiative means developing a new type of a social technology based on the capacities of both individual and collective levels; it also means having an open mind, open heart, and open will.

Having an open mind here refers to the ability to access intellectually (using IQ) but also seeing with fresh eyes. Open heart is the ability to access an object using emotional intelligence (EQ), which includes empathizing with others who are in a different context. And finally, open will refers to the ability to access with authentic purpose or spiritual intelligence (SQ). Together, these three types of openness allow handling the happening of letting go and letting come. In this context, leaders may face three barriers that obstruct the entrance to deeper territories. 
These are the voice of judgment (VOJ), the voice of cynicism (VOC), and the voice of fear (VOF). VOJ is the wall to an open mind, while VOC covers all types of emotional acts which are used to prevent our vulnerability. VOC shall be prevented because it hinders the progress from the bottom of $U$ and up. VOF averts us from letting go of who we are and what we have, it often assumes the fear of losing economic security, the fear of looking hilarious to others and even the fear of death.

Hence, we should let the old self go and open up for a new self. Only in a such a way we can step to another level and thus move to the upward side of the $U$ shape. The observing process constantly requires intuition or inner knowledge, only then the creativity will arise. The co-sensing movement stresses on sensing, whereas the co-presencing movement stresses on inner knowing. Finally, the co-creating movement stresses on performing.

Senge et al. (2004) claimed that creativity is important for health, happiness and all other aspects of life success. Creativity is present inside everyone, however, it is often covered by the voice of judgement.

To let creativity come out, we need patience and the willingness not to conceptualize into the framework what we see, but rather observe without formulating any conclusions. Social groups in their dynamics have coercive sharing of norms and ways of thought which is often effective, however, people also have to learn how to take time, assess independently and stop making unnecessary assumptions. For that reason, people should be more aware of their own thoughts.

This could be reached in two ways: one is very Eastern and is called meditation, and another one is Western and called contemplative. These two methods could help with slowing down thoughts and become cautiously aware.

Meditation (Senge et al., 2004) is often defined as improving our capacity purposefully by paying utmost attention to anything that may significantly help us maneuver in the world with open eyes and open hearts. Mediation is divided into two levels: concentration refers to the starting process of focusing and paying attention until an individual becomes less reactive and less irritated. The next one is mindfulness, when an individual is able to see a connection that may not has been seen before. Thus, this individual starts to develop more insightful awareness, beyond the everyday surface. It is beneficial if an individual has deeply nonjudgmental and non-dualistic awareness, then pain can disappear, sometimes completely. Buddhism theory teaches everything is interdependent, therefore, the world and the mind are inseparable.

When one is arriving at the bottom of $U$, how does knowing of the wholeness emerge? Let us introduce another important notion - to crystalize. As Masaru Emoto (cited in (Senge et al., 2004)) stated, human body consists mostly of water as well as the Earth surface is covered mostly by water than by land.

Crystalized water forms the most common substance on the globe, thus representing the power of reconnection. For example: the water from the sources which people respect, is always pure and healthy, and it is often known for its healing qualities. Crystals are complex and beautiful structures.

On the opposite side, polluted water is not. Thus, crystal water can be compared to purity and positive mind. Masaru Emoto has carried out an experiment with water forming into crystals when Mozart or folk music was on, and even polluted water after "listening" to praying for an hour got the crystal form. 


\section{THE INTEGRATION OF RELIGIOUS THEORY}

\section{Conclusion and recommendations}

Under the concept of Thailand 4.0, we are expected to develop human capital, knowledge, skills, especially soft skills for the future smart people and smart citizens with well-tuned ethics. Thailand aims to become a truly innovative nation. Recently, the government has started to reform the education system by proposing all educational institutions demonstrate their expert potential differently, through research, humanity and local culture preservation.

This reform has been launched because Thailand's education is now ranked the second lowest in the ASEAN as reported by the World Economic Forum (WEF). Ranking of education indirectly reflects the competitiveness of a country overall, since quality of education always impacts the quality of human resources (Ministry of Education, 2013). Under the current business disruptive paradigm, with its emphasis on ICT, having knowledge, skills and the right attitude are not enough for developing human capital. These days in underdeveloped and developing countries, majority of people trapped are in in the issues related to daily life expenses.

Social problems and human behavior seem to become more troublesome due to people's lack of consciousness. In other words, Thai society requires not just innovations and/or creativity boost. Of equally the same utmost importance are discipline, health, ethics and moral. Despite the fact the education reform has already started, it looks like all educational institutions in Thailand are still practicing teaching and learning under normative isomorphism, including TQF and quality assurance. However, this is also needed in order to find best practices and legitimacy to be accepted and survive in the world. Thai education institutions need to pass future global assessments with higher scores.

Thailand is known internationally as "the land of smiles", the majority of people in the country are Buddhists. This is the country that can actually implement religious education for living peacefully. Unfortunately, as of today, many Thai people are not well aware about the Buddhism concept, but are rather superstitious instead. What is more, their beliefs are often mixed up with other doctrines and rituals. Interestingly, many Western scholars seem to be more aware about how important the Buddhism concept can be as they are adapting it into the theory $\mathrm{U}$.

In a nutshell: our mind is peaceful without previous judgements or experiences, only then new knowledge and innovation will shine out. At first, it usually looks easy to be practicing your mind going deep down to the bottom of $U$, but in fact it is not at all. Figure 2 demonstrates the depth of trying to practice this. As university lecturers, we can teach our students about positive thinking, letting them sense the wholeness. This would shape and change internal thoughts, known as Manokarma. Then, manokarma would lead the way how we spend our life and how our life is affecting others and/or the environment.

In conclusion, the author would like to offer their own conceptual framework for education. It is based on reviewing and combining of the Eastern theory (Buddhism) and Western theory (Theory U).

Generally speaking, all brightest ideas of people arise from the peace of mind . Hence, integration of the Buddhism concepts known as Trisikkha or Sila , Samathi and "Panyā leads to discipline, peaceful mind and to seeing things as they are. Triskkha will generate inner knowledge. In this context, school should be as a learning organization where life-long learning is actively implemented and accessible for everyone. The access can be either 
online, or through face-to-face learning. The author is confident that new knowledge and innovation will emerge from the human inner wisdom, inner peace and harmony. When we understand ourselves, deeply knowing the whole, we would understand and empathize with others. From the business perspective, this would mean getting new competitive advantages, providing better customer services and generating innovations. From a more holistic view, system thinking and positive pure mind together make society better.

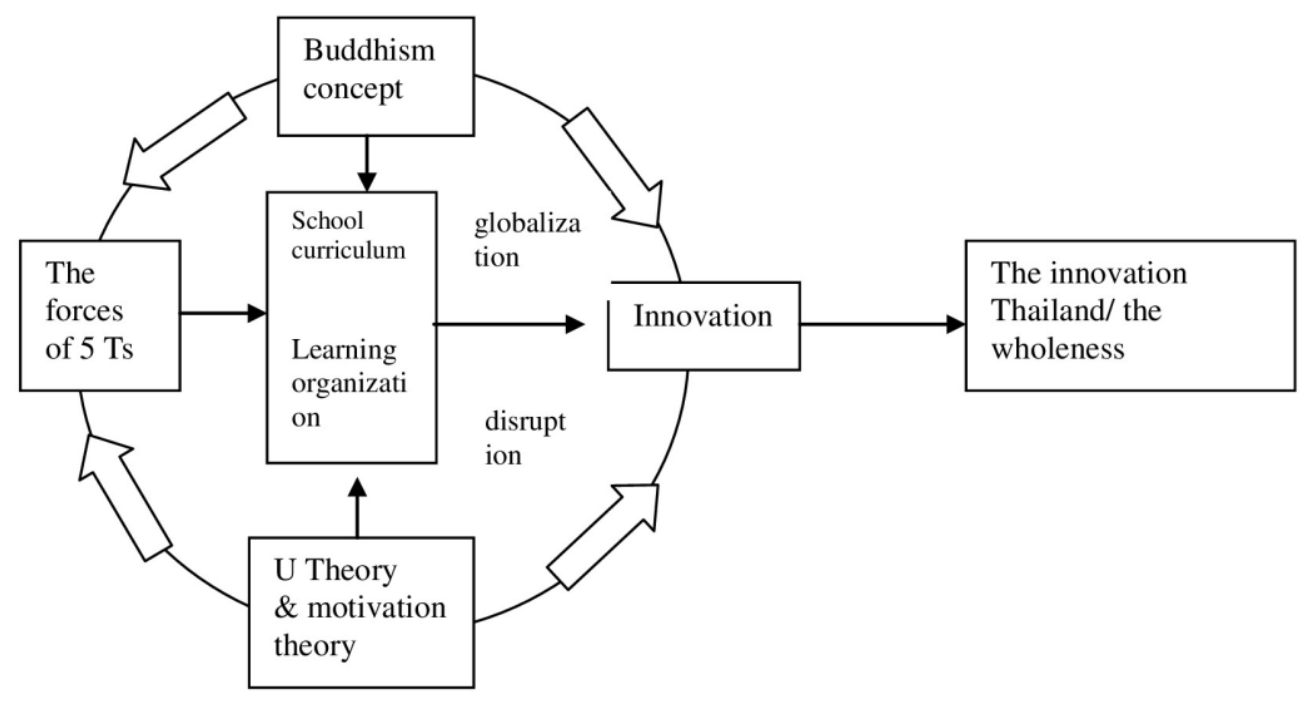

Figure 2 - The conceptual mix as suggested by the author for Thai education sector (Source: made by the author)

The forces of 4Ts or 5Ts as well as disruptive globalization overall are imposing frequent and dramatic changes on all of us. People who already embraced the $U$ theory along with the key Buddhism concepts would observe these changes and be able to adapt to them. Furthermore, people who have such capabilities would go further and deeper at the bottom of $\mathrm{U}$ and then reach the stability level of Samathi.

They would provoke their inner talents which everyone has individually. As mentioned earlier, under the ongoing globalization, businesses compete in services rather than products. Servicing as a science assumes systematic instructions which have dynamic value co-creation in relation to resources, people, technologies, organization and shared information (Maglio \& Spohrer, 2008). Hence, the model should also include learning to exploit tacit and explicit talents and also empathy, shared competences and so on. Connectedness of a whole system will eventually lead to success. 


\section{THE INTEGRATION OF RELIGIOUS THEORY}

\section{References:}

Abell, A. \& Oxbrow, N. (2001). Competing with knowledge: the information professional in the knowledge management age. London: Library Association Publishing.

Ananmana, K. et al. (2018). Thai Labor Requirements and Developing English Communication Skills in Rayong Province. The EUrASEANs, 6(13), 47-53.

Aston Centre for Human Resources. (2008). Strategic Human Resource Management. London: CIPD.

Becker, S. G. (1993). Human Capital: A Theoretical and Empirical Analysis with Special Reference to Education. London: University of Chicago Press Ltd.

Boonkong, T. (2006). Economics of Human Resources. Bangkok. O. S Printing House.

Changkwanyuen, P. (2017). Preecha's Vision on Humanities, Society and Education. Bangkok: Chula Press.

Donaldson, L. (2001). The Contingency Theory of Organizations. New Delhi: Sage Publications.

Dzinkowski, R. (2000). The Measurement and Management of Intellectual Capital: An Introduction. Management Accounting, 78(2), 32-36.

Goenka, S. N. (2019). Vipassana Meditation. Retrieved from: http://www.dhamma.org.

Hoy, K. W. \& Miskel, G. C. (2005). Educational Administration: Theory, Research, and Practice. Singapore: Mc GrawHill.

Jasimuddin, M., S. (2012). Knowledge Management: An Interdisciplinary Perspective. Hong Kong: World Scientific.

Kankaew, K. (2019). Is Human Capital in Higher Education Ready for Thailand 4.0: a Case Study of SSRUIC. Students Nakorn Pathom Education Center. Journal of Educational and Social Sciences, 19(3), 203-209.

Kraaijenbrink, J. (2011). The Oxford Handbook of Human Capital. Oxford: Oxford University Press.

Maglio, P. P., Spohrer, J. (2008). Fundamentals of Service Science. Journal of the Academic Marking Science, 36, 18-20.

Marquardt, J. M. (2002). Building the Learning Organization: Mastering the 5 elements for corporate learning. CA: Davies-Black Publishing.

Ministry of Education (2013). Thailand's Education Rearmost in ASEAN. Retrieved from: http://www.moe.go.th.

Pawet, W. (2002). The Human Life in the 21st Century: New Normal of Development. Bangkok: Sodsri Sadidwaong.

Phraphromkhunaphon. (2004). Political Science for nation vs Political Science for the World. Bangkok: Phim Suai.

Phraphromkhunaphon. (2010). How to think according to Buddhatham. Bangkok: Siam.

Razi, N. \& More, E. (2012). Human Capital and Performance Management in High-Performing Service Industry: A Case of the Impact of an Acquisition. Journal of Accounting-Business \& Management, 19(2), 15-43.

Senge, P. (2006). The Fifth Discipline: The Art and Practice of Learning Organization. Sydney: Doubleday. 
Senge, P., Scharmer, O. C., Jaworski, J., Flowers, S. B. (2004). Presence: Human Purpose and the Field of the Future. NY: Crown Business.

Scharmer, O. C. (2009). Theory U: Leading from the Future as IT Emerges. CA: Berrett-Koehler.

Schultz, W. T. (1980). Investing in People. London: University of California Press.

Tippawan, L. (2013). Organization Theory: Multi-Paradigm Perspectives. Bangkok: D.K. Printing World.

Ushakov, D. (2018). Post Industrialization in the Dynamics of Socioeconomic Transformations. The Euraseans, 6(13), 18-26.

Wykstra, A. R. (1971). Human Capital Formation and Manpower Development. NY: The Free Press.

Paper submitted

Paper accepted for publishing

Paper published online
16 March 2020

24 June 2020

31 July 2020 